\title{
Prevalence of vitamin D deficiency in urban south Indians with different grades of glucose tolerance
}

\author{
Ramamoorthy Jayashri, Ulagamathesan Venkatesan, Coimbatore S. Shanthirani, Mohan Deepa, \\ Ranjit Mohan Anjana, Viswanathan Mohan and Rajendra Pradeepa* \\ Madras Diabetes Research Foundation and Dr. Mohan's Diabetes Specialities Centre, WHO Collaborating Centre for \\ Non-communicable Diseases Prevention and Control and ICMR Centre for Advanced Research on Diabetes, Chennai, India
}

(Submitted 2 December 2019 - Final revision received 16 March 2020 - Accepted 17 March 2020 - First published online 26 March 2020)

Abstract

The present study assessed the prevalence of vitamin D deficiency in an urban south Indian population in individuals with different grades of glucose tolerance. A total of 1500 individuals (900 normal glucose tolerance (NGT), 300 prediabetes and 300 with type 2 diabetes mellitus (T2DM)) who were not on vitamin D supplementation were randomly selected from the Chennai Urban Rural Epidemiological Study follow-up study. Anthropometric, clinical examination and biochemical investigations (25-hydroxyvitamin D (25(OH)D), insulin, glycated $\mathrm{Hb}$ (HbA1c) and serum lipids) were measured. Vitamin D deficiency was defined as serum $25(\mathrm{OH}) \mathrm{D}<20 \cdot 0 \mathrm{ng} / \mathrm{ml}$, insufficiency as $20-29.9 \mathrm{ng} / \mathrm{ml}$ and sufficiency as $\geq 30 \mathrm{ng} / \mathrm{ml}$. Of the 1500 individuals studied, $45 \%$ were males and the mean age was 46 (sD 12 ) years. Vitamin D levels lowered with increasing degrees of glucose tolerance (NGT: 21 (SD 11); prediabetes: 19 (SD 10); T2DM: 18 (SD 11) ng/ml, $P<0.001)$. The overall prevalence of vitamin D deficiency was $55 \%$ and was significantly higher among individuals with T2DM (63\%) followed by prediabetes $(58 \%)$ and NGT $(51 \%)\left(P_{\text {for trend }}<0.001\right)$. Women had 1.6 times the risk of vitamin D deficiency compared with men (unadjusted OR $1.6(95 \% \mathrm{CI} 1.3,2 \cdot 0)$ and adjusted OR $1.6(95 \% \mathrm{CI} 1 \cdot 2,1.9))$. However, there was no increasing trend observed with increasing age. The prevalence of abdominal obesity (66 v. 49\%), generalised obesity ( $80 v .64 \%$ ), the metabolic syndrome ( $45 v .37 \%)$ and insulin resistance (38v. $27 \%)$ was significantly higher in those with vitamin D deficiency compared with those without. This study shows that vitamin D deficiency is highly prevalent in this urban south Indian population and was higher among individuals with T2DM and prediabetes compared with those with NGT.

\section{Key words: Vitamin D: Diabetes: Glucose tolerance: Prevalence: South Asians}

The study of vitamin D has been of great interest to the researchers for more than a century due to diverse spectrum of clinical and biochemical manifestations. There is emerging evidence from studies to show that vitamin D is not only required for bone health but also for the body to perform other physiological functions including cell differentiation, proliferation, insulin production and immune functions ${ }^{(1)}$. Low 25 -hydroxyvitamin D (25(OH)D) levels are associated with several disorders including diabetes, CVD, hypertension, cancer and even depression ${ }^{(2-4)}$.

Mild to moderate vitamin D deficiency has been identified as one of the risk factors for type 2 diabetes mellitus (T2DM), as it may affect glucose homoeostasis through increasing insulin resistance (IR) and reducing insulin secretion from $\beta$-cells of the pancreas ${ }^{(5)}$. Studies conducted in the west have shown that diabetes and prediabetes are associated with low serum concentrations of $25(\mathrm{OH}) \mathrm{D}^{(6,7)}$. A meta-analysis conducted based on observational studies concluded that there appears to be a consistent relationship between low 25(OH)D levels, T2DM and the metabolic syndrome (MetS) ${ }^{(8)}$

Previous reports suggest that vitamin D deficiency is present in more than $90 \%$ of Indians and other Asian countries, whereas it is about $40 \%$ in individuals in developed countries ${ }^{(9)}$. Very few population-based studies have been conducted to assess the prevalence of vitamin D deficiency across the spectrum of glucose intolerance in India ${ }^{(10,11)}$ or other developed countries ${ }^{(12,13)}$. Hence, this study was carried out to assess the prevalence of vitamin D deficiency in an urban south Indian population in individuals with different grades of glucose tolerance.

\section{Materials and methods}

The study participants were recruited from the Chennai Urban Rural Epidemiology Study (CURES) in whom a 10-year follow-

Abbreviations: BP, blood pressure; CURES, Chennai Urban Rural Epidemiology Study; IR, insulin resistance; MetS, metabolic syndrome; NGT, normal glucose tolerance; T2DM, type 2 diabetes mellitus; 25(OH)D, 25-hydroxyvitamin D.

* Corresponding author: Dr Rajendra Pradeepa, fax +91 44 28350935, email guhapradeepa@gmail.com 
up was conducted between 2012 and 2013. The methodology of the CURES has been published elsewhere ${ }^{(14,15)}$. Of the 3589 individuals followed-up, 645 individuals were lost to follow-up (18\%) and 534 individuals died (14.9\%). From the remaining 2410 individuals, 1500 individuals were randomly selected for this study. The details of their recruitment are described elsewhere ${ }^{(16)}$. The exclusion criteria for this study included those who had T2DM, diabetes secondary to other diseases, for example, chronic pancreatitis, those aged $<20$ years or $>80$ years or those taking vitamin D supplements.

The study was approved by the Institutional Ethics Committee of the Madras Diabetes Research Foundation, Chennai, Tamil Nadu, India, and written informed consent was obtained from all the participants. For each individual, a detailed questionnaire was administered to collect information about demographic and socio-economic parameters, medical history, family history diabetes and dietary pattern and behavioural factors. Anthropometric details such as height, weight and waist were measured using standardised techniques ${ }^{(17)}$. Blood pressure (BP) was measured using a mercury sphygmomanometer and was recorded in the sitting position in the right arm. Two readings were taken 5 min apart, and the mean of the two was recorded as the BP.

A fasting venous blood sample was collected after an overnight fast of at least $10 \mathrm{~h}$ for the estimation of biochemical investigations for recruited study participants. The sample was centrifuged to extract serum for the estimations of glucose, lipids and $25(\mathrm{OH}) \mathrm{D}$, and the whole blood was used for the estimation of HbA1c. Biochemical analyses were performed in a laboratory certified by the National Accreditation Board for Testing and Calibration Laboratories and the College of American Pathologists. Serum insulin and serum 25(OH)D concentrations were estimated using the electrochemiluminescence using a Roche e601Cobas immunoassay analyzer (Roche Diagnostics). The intra- and inter-assay CV for vitamin D assay were 3.6 and $6.4 \%$, respectively.

\section{Definitions}

- Normal glucose tolerance (NGT): 2-h post-load glucose was $<140 \mathrm{mg} / \mathrm{dl} \quad(7 \cdot 8 \mathrm{mmol} / \mathrm{l})$ and fasting plasma glucose $<110 \mathrm{mg} / \mathrm{dl}(6 \cdot 1 \mathrm{mmol} / \mathrm{l})^{(18)}$.

- Impaired fasting glucose: Fasting plasma glucose $\geq 110$ $\mathrm{mg} / \mathrm{dl}(6 \cdot 1 \mathrm{mmol} / \mathrm{l})$ and $<126 \mathrm{mg} / \mathrm{dl}(7 \cdot 0 \mathrm{mmol} / \mathrm{l})$ and $2 \mathrm{~h}$ post-glucose value $<140 \mathrm{mg} / \mathrm{dl}(7.8 \mathrm{mmol} / \mathrm{l})^{(18)}$.

- Impaired glucose tolerance: 2 -h post-glucose $\geq 140 \mathrm{mg} / \mathrm{dl}$ $(7.8 \mathrm{mmol} / \mathrm{l})$ but $<200 \mathrm{mg} / \mathrm{dl}(11.1 \mathrm{mmol} / \mathrm{l})$ and fasting value $<126 \mathrm{mg} / \mathrm{dl}(7 \cdot 0 \mathrm{mmol} / \mathrm{l})^{(18)}$.

Prediabetes: Individuals with impaired fasting glucose or impaired glucose tolerance or both.

- T2DM: Fasting plasma glucose $\geq 126 \mathrm{mg} / \mathrm{dl}(7 \cdot 0 \mathrm{mmol} / \mathrm{l})$ or $2 \mathrm{~h}$ post-load glucose level $\geq 200 \mathrm{mg} / \mathrm{dl}(11 \cdot 1 \mathrm{mmol} / \mathrm{l})$, or a past medical history (self-reported diabetes under treatment by a physician), or drug treatment for diabetes $^{(18)}$.

- Vitamin D deficiency: Defined as serum 25(OH)D levels $<20 \mathrm{ng} / \mathrm{ml}^{(19)}$

- Vitamin D insufficiency: Defined as serum 25(OH)D levels ranging between 20 and $29.9 \mathrm{ng} / \mathrm{ml}^{(19)}$
Vitamin D sufficiency: Defined as serum 25(OH)D levels $\geq 30 \mathrm{ng} / \mathrm{ml}^{(19)}$

- BMI was calculated using the formula: weight (in $\mathrm{kg}$ ) divided by height (in $\mathrm{m}^{2}$ )

- Obesity: Generalised obesity (BMI $\geq 25 \mathrm{~kg} / \mathrm{m}^{2}$ ) and abdominal obesity (waist circumference $\geq 90 \mathrm{~cm}$ in males and $\geq 80 \mathrm{~cm}$ in females) were defined using WHO Asia Pacific guidelines ${ }^{(20)}$.

- Hypertension: Diagnosed in subjects who were on antihypertensive medications or had a systolic $\mathrm{BP} \geq 140 \mathrm{mmHg}$ and/or a diastolic $\mathrm{BP} \geq 90 \mathrm{mmHg}^{(21)}$.

- IR: IR was calculated using the Homeostasis Model Assessment formula: fasting insulin $(\mathrm{mIU} / \mathrm{ml}) \times$ fasting glucose $(\mathrm{mmol} / \mathrm{l}) / 22 \cdot 5)^{(22)}$.

- MetS: The MetS was defined according to the National Cholesterol Education Program ATP III criteria modified for waist according to WHO Asia Pacific guidelines for obesity. The MetS was defined as the presence of any three of the following abnormalities: abdominal obesity, defined as waist circumference of $\geq 90 \mathrm{~cm}$ for men and $\geq 80 \mathrm{~cm}$ for women; high BP (systolic BP $\geq 130 \mathrm{mmHg}$ or diastolic $\mathrm{BP} \geq 85 \mathrm{mmHg}$ ); elevated fasting glucose (fasting plasma glucose level $\geq 100 \mathrm{mg} / \mathrm{dl}(5.6 \mathrm{mmol} / \mathrm{l})$; (TAG $\geq 1.7 \mathrm{mmol} / \mathrm{l})$ ) or low HDL-cholesterol $(<1.03$ $\mathrm{mmol} / \mathrm{l}$ for males, $<1.3 \mathrm{mmol} / \mathrm{l}$ for females) ${ }^{(23,24)}$.

\section{Statistical analysis}

Statistical analyses were performed with SPSS statistical package (version 22.0; SPSS Inc.). Continuous variables are reported as mean values and standard deviations. Categorical variables are reported in percentages. One-way ANOVA with post hoc Tukey honestly significant difference or Student's $t$ test was used to compare groups for continuous variables, and the $\chi^{2}$ test was used to compare proportions between two groups. Univariate logistic regression analysis was performed to look at the association of glucose tolerance, age and sex with vitamin D deficiency in our population. Logistic regression models were used to measure the association of vitamin D deficiency with various factors like diabetes, prediabetes, dysglycaemia, abdominal and generalised obesity, hypertension, the Mets and IR. $P$ values of $<0.05$ were considered as statistically significant.

\section{Results}

\section{Basic characteristics of the study participants}

A total of 1500 participants were included in the study, which comprised 900 NGT, 300 prediabetes and 300 T2DM individuals. The study population included $45 \%$ of males and the mean age was 46 (sD 12) years. Individuals with T2DM were older (T2DM: 54 (SD 11) years; prediabetes: 48 (SD 12) years; NGT: 43 (SD 11) years; $P<0.001)$ and had a higher systolic BP (T2DM: 132 (SD 19) $\mathrm{mmHg}$; prediabetes: 129 (sD 20) $\mathrm{mmHg}$; NGT: 123 (sD 18) $\mathrm{mmHg} ; \quad P<0.001$ ) compared with individuals with prediabetes and NGT. In addition, individuals with T2DM and prediabetes had a higher BMI (T2DM: 27 (sD 5) kg/m²; prediabetes: 27 (sD 5) kg/m²; NGT: 26 (sD 5) $\mathrm{kg} / \mathrm{m}^{2} ; P<0 \cdot 001$ ) and waist circumference (T2DM: 90 (sD 10) cm; prediabetes: 90 (sD 11) cm; NGT: 86 (sD 11) cm; $P<0.001$ ) compared with 
NGT subjects. Similar trend was observed with hypertension (T2DM: $73 \%$; prediabetes: $29 \%$; NGT: $23 \%$; $P<0.001$ ) when compared with individuals with NGT. There was an increasing trend in fasting insulin (T2DM: 11 (SD 7) $\mu \mathrm{IU} / \mathrm{ml}$; prediabetes: 8 (sD 6) $\mu \mathrm{IU} / \mathrm{ml}$; NGT: 8 (sD 5) $\mu \mathrm{IU} / \mathrm{ml} ; P<0.001$ ), total cholesterol (T2DM: 5 (sD 1) $\mathrm{mmol} / \mathrm{l}$; prediabetes: 5 (SD 1$)$ mmol/l; NGT: 5 (sD 1) mmol/l; $P<0.001$ ) and TAG levels (T2DM: 2 (sD 2) mmol/l; prediabetes: 2 (sD 1) mmol/l; NGT: 1 (sD 0.9 ) $\mathrm{mmol} / \mathrm{l} ; \quad P<0.001$ ) with decreasing glucose tolerance. Among the T2DM participants, the mean duration of diabetes was 7 (SD 6) years and $65 \%$ of them had a family history of diabetes. Overall, $94 \%$ followed a non-vegetarian meal pattern (T2DM: $91 \%$; prediabetes: $93 \%$; NGT: $95 \%$; $P=0.005$ ).

Table 1 describes the basic clinical and biochemical characteristics of the study population with sufficient, insufficient and deficient serum $25(\mathrm{OH}) \mathrm{D}$ levels. Individuals with vitamin D deficiency had higher BMI (deficient: 27 (SD 5) mmHg; sufficient: 25 (sD 5) mmHg; $P<0 \cdot 001$ ), HbA1c (deficient: 6 (sD 2) \%; sufficient: 6 (sD 1)\%; $P<0.001$ ), Homeostasis Model Assessment IR (deficient: 2 (sD 2); sufficient: 2 (sD 2); $P<0.001$ ) when compared with vitamin $\mathrm{D}$ sufficient groups. There were no significance observed in BP and lipid parameters.

\section{Mean serum 25-hydroxyvitamin D levels and prevalence of vitamin D deficiency}

Fig. 1(a) shows the mean values of $25(\mathrm{OH}) \mathrm{D}$ levels in participants with different degrees of glucose tolerance. The overall $25(\mathrm{OH}) \mathrm{D}$ level for the entire study population was $20 \mathrm{ng} / \mathrm{ml}$. The mean levels of 25(OH)D were 21, 19 and $18 \mathrm{ng} / \mathrm{ml}$ in individuals with NGT, prediabetes and T2DM participants, respectively (ANOVA, $P<0 \cdot 001$ ). Individuals with prediabetes and T2DM had significantly lower levels of 25(OH)D compared with individuals with NGT. The distribution of $25(\mathrm{OH}) \mathrm{D}$ levels in the entire study participants ( $n$ 1500) showed that only $16 \%$ ( $n 240)$ had normal 25(OH)D levels, 29\% ( $n$ 437) had insufficient $25(\mathrm{OH}) \mathrm{D}$ levels and $55 \%(n 823)$ had deficient $25(\mathrm{OH}) \mathrm{D}$ levels. Fig. 1(b) shows the prevalence of vitamin D deficiency in individuals with different degrees of glucose tolerance. The highest prevalence of vitamin D deficiency was observed among individuals with T2DM (63\%) followed by prediabetes $(58 \%)$ and NGT (51\%) (trend $\chi^{2} 14.24, P<0.001$ ). An increasing trend of vitamin $\mathrm{D}$ deficiency was observed with increasing glucose tolerance. If serum $25(\mathrm{OH}) \mathrm{D}$ levels $<30 \mathrm{ng} / \mathrm{ml}$ were used for

Table 1. Basic clinical and biochemical characteristics of participants with sufficient, insufficient and deficient serum 25-hydroxyvitamin $D(25(\mathrm{OH}) \mathrm{D})$ levels (Mean values and standard deviations; numbers and percentages)

\begin{tabular}{|c|c|c|c|c|c|c|}
\hline \multirow[b]{3}{*}{ Variables } & \multicolumn{6}{|c|}{ Serum 25(OH)D levels } \\
\hline & \multicolumn{2}{|c|}{ Sufficient ( $n$ 823) } & \multicolumn{2}{|c|}{ Insufficient ( $n$ 437) } & \multicolumn{2}{|c|}{ Deficient ( $n$ 240) } \\
\hline & Mean & SD & Mean & SD & Mean & SD \\
\hline Age (years) & 46 & 11 & 46 & 12 & 46 & 12 \\
\hline Sex (male) $\ddagger$ & \multirow{3}{*}{\multicolumn{2}{|c|}{$\begin{array}{r}145 \\
60\end{array}$}} & \multirow{3}{*}{\multicolumn{2}{|c|}{$\begin{array}{c}202^{*} \\
46\end{array}$}} & \multirow{3}{*}{\multicolumn{2}{|c|}{$\begin{array}{c}321^{*} \dagger \\
39\end{array}$}} \\
\hline$n$ & & & & & & \\
\hline$\%$ & & & & & & \\
\hline Height (cm) & 160 & 10 & $160^{\star *}$ & 10 & $160^{*}$ & 10 \\
\hline Weight (kg) & 64 & 12 & 64 & 12 & $67^{\star \star}+\dagger$ & 14 \\
\hline BMI $\left(\mathrm{kg} / \mathrm{m}^{2}\right)$ & 25 & 5 & 26 & 5 & $27^{*} \dagger$ & 5 \\
\hline Waist (cm) & 86 & 10 & 86 & 11 & $88+\dagger$ & 12 \\
\hline Systolic blood pressure $(\mathrm{mmHg})$ & 130 & 20 & 130 & 20 & 130 & 20 \\
\hline Diastolic blood pressure $(\mathrm{mmHg})$ & 79 & 12 & 79 & 12 & 78 & 11 \\
\hline Fasting plasma sugar $(\mathrm{mmol} / \mathrm{l})$ & 6 & 2 & 6 & 2 & $6^{\star *}$ & 2 \\
\hline $\mathrm{HbA1c}(\%)$ & 6 & 1 & 6 & 1 & $6^{*}+\dagger$ & 2 \\
\hline Fasting insulin $(\mu \mathrm{IU} / \mathrm{ml})$ & 8 & 6 & 8 & 6 & $9^{* \star}+\dagger$ & 6 \\
\hline $\begin{array}{l}\text { Homeostasis model assessment of } \\
\text { insulin resistance }\end{array}$ & 2 & 2 & 2 & 2 & $2^{\star \star}+\dagger$ & 2 \\
\hline Cholesterol (mmol/l) & 5 & 1 & 5 & 1 & 5 & 1 \\
\hline TAG (mmol/l) & 2 & 1 & 2 & 1 & 2 & 1 \\
\hline $\mathrm{HDL}(\mathrm{mmol} / \mathrm{l})$ & 1 & 0.2 & 1 & 0.2 & 1 & 0.2 \\
\hline $\mathrm{LDL}(\mathrm{mmol} / \mathrm{l})$ & 3 & 1 & 3 & 1 & 3 & 1 \\
\hline VLDL (mmol//) & 0.03 & 0.03 & 0.03 & 0.03 & 0.03 & 0.03 \\
\hline Cholesterol:HDL ratio & 5 & 1 & 5 & 1 & 5 & 1 \\
\hline \multicolumn{7}{|c|}{ Household income (Indian Rupees/month) } \\
\hline \multicolumn{7}{|c|}{ Low $(<=$ Rs. 5000 (USD < 70)) } \\
\hline$n$ & \multicolumn{2}{|c|}{44} & \multicolumn{2}{|c|}{93} & \multicolumn{2}{|c|}{190} \\
\hline$\%$ & \multicolumn{2}{|c|}{18} & \multicolumn{2}{|c|}{21} & \multicolumn{2}{|c|}{23} \\
\hline \multicolumn{7}{|c|}{ Medium (Rs. 5001-10000 (USD 70-140)) } \\
\hline$n$ & \multirow{2}{*}{\multicolumn{2}{|c|}{$\begin{array}{r}139 \\
58\end{array}$}} & \multirow{2}{*}{\multicolumn{2}{|c|}{$\begin{array}{r}235 \\
54\end{array}$}} & \multirow{2}{*}{\multicolumn{2}{|c|}{$397^{* \star}+\dagger$}} \\
\hline$\%$ & & & & & & \\
\hline \multicolumn{7}{|l|}{ High (>10 000 (USD > 140)) } \\
\hline$n$ & \multirow{2}{*}{\multicolumn{2}{|c|}{$\begin{array}{l}57 \\
24\end{array}$}} & \multirow{2}{*}{\multicolumn{2}{|c|}{$\begin{array}{r}109 \\
25\end{array}$}} & \multirow{2}{*}{\multicolumn{2}{|c|}{$\begin{array}{r}236 \\
29\end{array}$}} \\
\hline$\%$ & & & & & & \\
\hline
\end{tabular}

${ }^{*} P<0.001$ and ${ }^{* *} P<0.05$ compared with individuals with sufficient serum 25(OH)D levels.

$\dagger P<0.001$ and $\dagger \dagger P<0.05$ compared with individuals with insufficient serum $25(\mathrm{OH}) \mathrm{D}$ levels.

$\ddagger \chi^{2}$. 

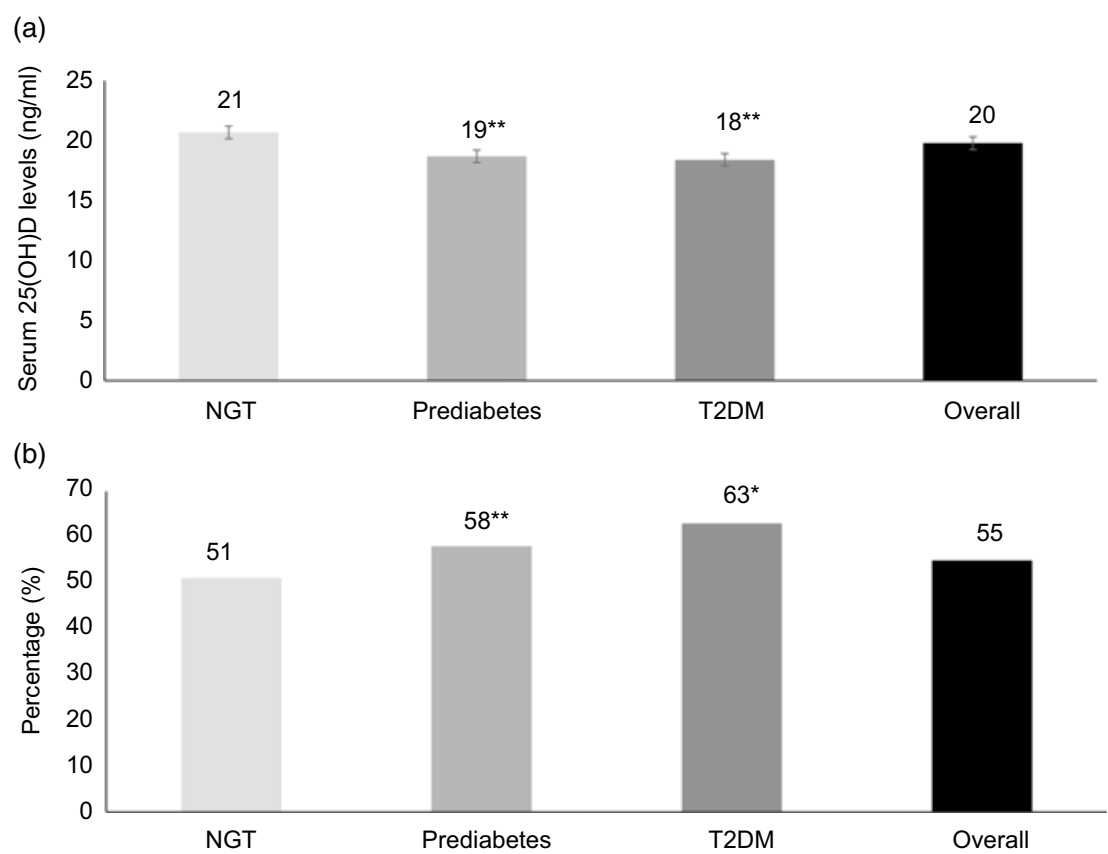

Fig. 1. Mean serum levels of 25-hydroxyvitamin $D(25(\mathrm{OH}) \mathrm{D})(\mathrm{a})$ and prevalence of vitamin $\mathrm{D}$ deficiency (b) in different degrees of glucose tolerance. ${ }^{*} P<0.001$ and ${ }^{\star \star} P<0.05$ compared with normal glucose tolerance (NGT). T2DM, type 2 diabetes mellitus.

Table 2. Association of age and sex with vitamin D deficiency ( $n$ 1500)

(Mean values and standard deviations; odds ratios and $95 \%$ confidence intervals)

\begin{tabular}{|c|c|c|c|c|c|c|c|}
\hline Sub-groups & Mean & SD & Vitamin D deficiency (\%) & Unadjusted OR & $95 \% \mathrm{Cl}$ & Adjusted OR* & $95 \% \mathrm{Cl}$ \\
\hline \multicolumn{8}{|l|}{ Age } \\
\hline$\leq 40$ years & 20 & 10 & 54 & 1.00 & & 1.00 & \\
\hline $41-50$ years & 20 & 10 & 54 & 0.98 & $0 \cdot 8,1 \cdot 3$ & 0.95 & $0.7,1 \cdot 2$ \\
\hline$\geq 51$ years & 20 & 12 & 57 & $1 \cdot 1$ & $0.9,1.4$ & $1 \cdot 1$ & $0.8,1.5$ \\
\hline \multicolumn{8}{|l|}{ Sex } \\
\hline Men & 22 & 11 & 48 & 1.00 & & 1.00 & \\
\hline Women & $19 \dagger$ & 10 & $60 \dagger$ & 1.6 & $1 \cdot 3,2$ & 1.6 & $1 \cdot 2,1 \cdot 9$ \\
\hline
\end{tabular}

${ }^{*}$ Adjusted for each other and further adjusted for BMI, systolic blood pressure, serum TAG, household income, dietary pattern and diabetes duration and medication. $\dagger P<0.001$.

defining vitamin D deficiency, we found the overall prevalence of vitamin D deficiency to be $84 \%$, with the highest prevalence observed among diabetic individuals (90\%) followed by prediabetes $(87 \%)$ and NGT $(81 \%)$.

Table 2 provides the prevalence and association of age and sex with vitamin D deficiency in the study population ( $n$ 1500). The mean serum $25(\mathrm{OH}) \mathrm{D}$ levels were lower in women compared with men (women $v$. men: 19 (SD 10) v. 22 (sD 11); $P<0 \cdot 001)$. There was no significant difference of $25(\mathrm{OH}) \mathrm{D}$ levels in different age groups (trend $\chi^{2}-0 \cdot 83, P=0.4$ ).

Fig. 2 presents the prevalence of obesity, hypertension, MetS and IR among individuals with sufficient, insufficient and deficient serum $25(\mathrm{OH}) \mathrm{D}$ levels. There was a significant increase in generalised obesity $(P<0.001)$, abdominal obesity $(P<0.001)$, the MetS $(P=0.02)$ and IR $(P=0.003)$ among individuals with vitamin $\mathrm{D}$ deficiency compared with those with sufficient $25(\mathrm{OH}) \mathrm{D}$ levels. The prevalence of vitamin D deficiency was 80 and $66 \%$ among participants with generalised and abdominal obesity, respectively, 35, 45 and $38 \%$ among those with hypertension, MetS and IR, respectively.

\section{Association of vitamin D deficiency with diabetes, prediabetes and other factors}

Multiple logistic regression analysis was done using vitamin D deficiency as the dependent variable. Individuals with diabetes and prediabetes had 1.6 times and 1.3 times risk for developing vitamin $D$ deficiency even after adjusting for confounding factors including age, female sex, abdominal obesity, hypertension, family history of diabetes, dietary pattern and income (diabetes OR 1.6 (95\% CI 1.1 2.2), $P=0.005$; prediabetes OR 1.3 (95\% CI $1,1 \cdot 8), P=0 \cdot 04)$. In addition, logistic regression models were used to measure the association of vitamin D deficiency with various factors (Fig. 3). It was observed that the dysglycaemia (unadjusted OR: 1.9, $P<0 \cdot 001$; adjusted OR: 1.5, $P=0 \cdot 001$ ), abdominal obesity (unadjusted OR: 1.8, $P<0 \cdot 001$; adjusted 


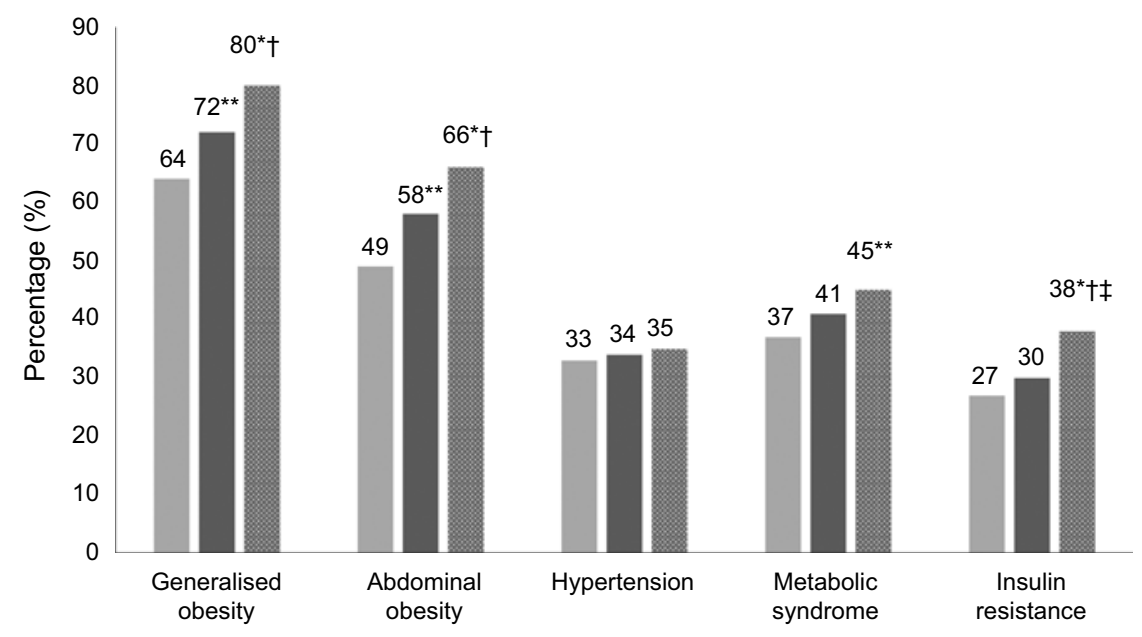

Fig. 2. Prevalence of obesity, hypertension, the metabolic syndrome and insulin resistance among individuals with sufficient, insufficient and deficient serum 25 -hydroxy-

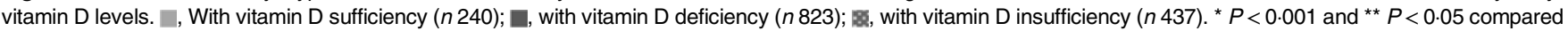
with sufficiency group. $\dagger P<0.05$ compared with insufficiency group. $¥$ Data available in $1440 / 1500$ individuals.

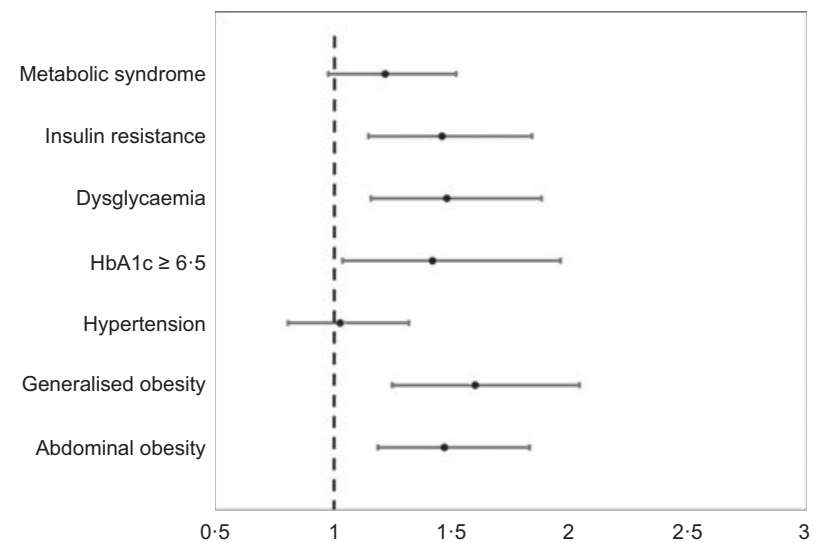

Fig. 3. Association of vitamin $D$ deficiency with various factors. ${ }^{*}$ Adjusted for age, sex, income, vegetarianism and duration of diabetes.

OR: $1 \cdot 5, P<0 \cdot 001$ ), generalised obesity (unadjusted OR: $1 \cdot 9$, $P<0 \cdot 001$; adjusted OR: $1 \cdot 6, P<0 \cdot 001$ ), glycaemic control (unadjusted OR: $1.8, P=0 \cdot 007$; adjusted OR: $1 \cdot 4, P=0.03)$ and IR (unadjusted OR: $1.5, P=0.02$; adjusted OR: $1.5, P=0.002$ ) had higher OR for vitamin D deficiency even after adjusting for age, sex, income, dietary pattern and duration of diabetes. However, there was no significant association observed between hypertension, the MetS and vitamin D deficiency.

\section{Discussion}

This is the first study from southern India to our knowledge, to determine the levels of serum $25(\mathrm{OH}) \mathrm{D}$ among individuals with NGT, prediabetes and T2DM. We report the overall prevalence of vitamin D deficiency to be $55 \%$ based on the serum 25(OH)D cut-off value of $<20 \mathrm{ng} / \mathrm{ml}^{(19)}$. A cross-sectional study conducted in south Indian adult urban and rural population residing in Tirupati, South India, reported that two-thirds of the population had low levels of $25(\mathrm{OH}) \mathrm{D}(54 \%$ - vitamin D insufficiency $(<20 \mathrm{ng} / \mathrm{ml})$ and $15 \%-$ vitamin D deficiency $(<10 \mathrm{ng} / \mathrm{ml}))^{(25)}$.
Thus, a total of $69 \%$ had serum $25(\mathrm{OH}) \mathrm{D}<20 \mathrm{ng} / \mathrm{ml}$, which is higher than the prevalence reported in our study.

The highest prevalence of vitamin D deficiency was observed among diabetic individuals (63\%) followed by prediabetes (58\%) and NGT (51\%). Modi et al. ${ }^{(11)}$ had reported $85 \%$ prevalence of vitamin D deficiency in a clinic-based cross-sectional, observational study at two tertiary level hospitals located in South India and North India and had reported the prevalence of vitamin D deficiency to be $84 \%$ among individuals with diabetes, $77 \%$ among those with prediabetes and $87 \%$ among individuals with NGT. In this study, the investigators considered vitamin D deficiency as serum $25(\mathrm{OH}) \mathrm{D}<30 \mathrm{ng} / \mathrm{ml}$. When this cut-off was used in our study, we found a similar overall prevalence of vitamin D deficiency (84\%), where $90 \%$ vitamin D deficiency was observed among diabetic individuals, followed by prediabetes (87\%) and NGT (81\%).

There are many studies, which have reported on prevalence of vitamin D deficiency in healthy populations in both Western population ${ }^{(26-29)}$ as well as Indian population ${ }^{(25,30-32)}$. However, there are no data, which reports on the prevalence of vitamin D deficiency in individuals with glucose tolerance. Of the 11247 Australian adults aged $\geq 25$ years studied in the Australian Diabetes, Obesity and Lifestyle (AusDiab) study, $4 \%$ had vitamin D deficiency (vitamin $\mathrm{D}<25 \mathrm{ng} / \mathrm{ml})^{(26)}$. Another study conducted in Isfahan, in the central part of Iran among 1111 healthy individuals (243 men and 868 women) aged between 20 and 80 years, reported the prevalence of vitamin D deficiency to be $50 \cdot 8 \%{ }^{(30)}$. The prevalence of vitamin D deficiency is more or less same even among the healthy NGT population in South India (51\%) compared with these studies.

A study conducted in 1052 women attending a gynaecology clinic in Agra, North India reported the prevalence of vitamin D deficiency with $25(\mathrm{OH}) \mathrm{D}$ level $<20 \mathrm{ng} / \mathrm{ml}$ to be $64 \%$ and those with the level of vitamin $\mathrm{D}<30 \mathrm{ng} / \mathrm{ml}$ to be $98 \%{ }^{(33)}$. In our study, we observed prevalence of vitamin D deficiency in $55 \%$ with $25(\mathrm{OH}) \mathrm{D}$ levels $<20 \mathrm{ng} / \mathrm{ml}$ and in $84 \%$ with $25(\mathrm{OH}) \mathrm{D}$ levels $<30 \mathrm{ng} / \mathrm{ml}$. 
Many studies have reported a higher prevalence of vitamin D deficiency among women than men. A study carried out in a tertiary care hospital in Secunderabad ${ }^{(34)}$ had reported higher prevalence of vitamin D deficiency in females than males. Modi et al. ${ }^{(11)}$ also reported similar results. Harinarayan et al. ${ }^{(35)}$ who studied healthy urban and rural adults also reported higher prevalence of vitamin D deficiency among women compared with men in both urban (62\% men $v .75 \%$ women) and rural areas ( $44 \%$ men $v .70 \%$ women). In our study, also similar findings were found and the vitamin D deficiency was 1.6 times higher in women when compared with men. In contrast, Marwaha et al. ${ }^{(32)}$ reported that there was no significant difference in prevalence of vitamin D deficiency between both sex.

It has been reported that low $25(\mathrm{OH}) \mathrm{D}$ levels play an important role in the pathogenesis of T2DM. Several physiological mechanisms have been put forward including the effect of vitamin D on insulin secretion and a direct effect of Ca and vitamin $\mathrm{D}$ on insulin action ${ }^{(36,37)}$. There is evidence to show that vitamin $\mathrm{D}$ therapy improves glucose tolerance and $\mathrm{IR}^{(38,39)}$. There are studies, both in the West and Indian subcontinent, that have reported that vitamin $\mathrm{D}$ deficiency is associated with $\mathrm{T}_{2} \mathrm{DM}^{(11,40-44)}$ and prediabetes ${ }^{(10,44-48)}$. The recent Hitachi Health Study ${ }^{(41)}$ conducted in Japanese adults concluded that higher circulating vitamin D was associated with a lower risk of T2DM, and this association was stronger among individuals with prediabetes. A study conducted in South India among 4628 patients with T2DM had shown that $71.4 \%$ were vitamin $\mathrm{D}$ deficient, $15 \%$ were vitamin $\mathrm{D}$ insufficient and $13.6 \%$ were found to have normal 25(OH)D levels ${ }^{(49)}$. Among the participants of the Asian Indian Diabetic Heart Study/Sikh Diabetes Study, $83 \%$ of T2DM participants was vitamin D deficient compared with $68 \%$ among normoglycaemic controls ${ }^{(43)}$. In the present study, we observed that $63 \%$ of T2DM individuals had vitamin D deficiency. Additionally, a significantly higher proportion of individuals with T2DM had vitamin D deficiency compared those with prediabetes and NGT. Similar observations have been reported in T2DM patients from the area of Athens and Pireaus ${ }^{(50)}$ and Saudi Arabia ${ }^{(51)}$.

Lower serum 25(OH)D levels were positively associated with prediabetes in the third National Health and Nutrition Examination Survey conducted in the USA ${ }^{(46)}$. The present study shows that $58 \%$ of the individuals with prediabetes were vitamin D deficient compared with those with NGT (51\%). While studies conducted in Mysuru ${ }^{(47)}$ and North India ${ }^{(48)}$ reported a higher prevalence of vitamin D deficiency compared with our study (73 and $69 \%$, respectively), a study conducted in West Bengal $^{(10)}$ reported a lower prevalence of vitamin D deficiency (44\%) among individuals with prediabetes, all using the same cut-off for vitamin D deficiency (serum 25(OH)D $<20 \mathrm{ng} / \mathrm{ml}$ ).

Vitamin D deficiency may also be a risk factor for $\mathrm{IR}^{(52)}$ as well as the MetS ${ }^{(53)}$. However, associations of vitamin D with IR have been inconsistent ${ }^{(54-56)}$. Analysis of 712 subjects after evaluating serum $25(\mathrm{OH}) \mathrm{D}$ levels and assessing insulin sensitivity by means of the homoeostasis model of IR reported that serum 25(OH)D was significantly correlated with IR and $\beta$-cell function in their multiethnic sample ${ }^{(56)}$. A study conducted in 2005 also reported the association of vitamin D deficiency with the MetS among US adults $^{(53)}$. In our study also, we found similar association of vitamin D deficiency with IR and the MetS. Several studies reported that the association between low 25(OH)D levels and the MetS was more pronounced in overweight and obese people than in normal-weight individuals ${ }^{(57)}$.

Over the past decade, various studies have reported an association between vitamin D deficiency and obesity. A systematic review and meta-analysis on vitamin D deficiency and obesity concluded that vitamin D deficiency was associated with obesity irrespective of age, latitude, cut-offs to define vitamin D deficiency and the Human Development Index of the study location ${ }^{(58)}$. A landmark study conducted by researchers of the Framingham Heart Study measured serum 25(OH)D levels in 3890 third-generation participants without CVD and diabetes reported lower $25(\mathrm{OH}) \mathrm{D}$ levels with greater BMI that could not be accounted for in variations in physical activity or diet. The study also reported an inverse relationship between serum $25(\mathrm{OH}) \mathrm{D}$ and subcutaneous and visceral adiposity even among lean individuals ${ }^{(59)}$. A retrospective study done in 170 individuals in Turkey also reported an association of vitamin D deficiency (serum $25(\mathrm{OH}) \mathrm{D}<25 \mathrm{ng} / \mathrm{ml}$ ) with obesity ${ }^{(60)}$. In our study, we observed an association of vitamin D deficiency with abdominal as well as generalised obesity. For individuals with abdominal obesity, the risk for vitamin D deficiency was 1.5 times higher than those without abdominal obesity, while it was 1.6 times more in those with generalised obesity.

The increasing prevalence of vitamin D deficiency in our country could be attributed to high melanin skin content, lack of sunlight exposure, clothing habits (well covered even when out in the sun), inadequate dietary consumption of foods rich in vitamin $\mathrm{D}$ due to predominant vegetarian dietary habits and limited availability of fortified foods ${ }^{(61)}$. In addition, increase in the number of hours spent indoors due to modernisation and changing work culture especially in urban Indians could be one of the reasons for high prevalence of vitamin D deficiency ${ }^{(62)}$. Some studies have shown that atmospheric pollution plays a role in reducing the efficiency of serum 25(OH)D photosynthesis as pollution scatters short UVB wavelengths ${ }^{(63)}$. There is a report of high incidence of vitamin D deficiency rickets in toddlers living in areas of high atmospheric pollution in Delhi, India $\left(28 \cdot 35^{\circ} \mathrm{N}\right)^{(64,65)}$.

The strengths of the study are that study participants were recruited from a population-based study in an ethnic group with a high prevalence of T2DM. Moreover, careful inclusion and exclusion criteria were used. Individuals were classified into different grades of glucose tolerance, namely, NGT, prediabetes and T2DM using oral glucose tolerance test. One of the limitations of the study is that being a cross-sectional design, we are unable to demonstrate a cause and effect relation between serum 25(OH)D with T2DM. Moreover, we do not have the details of sunlight exposure in these individuals.

In summary, our study reports the following findings: Firstly, serum 25(OH)D levels lowered with increasing severity of glucose tolerance. Secondly, the mean serum 25(OH)D levels were lower in women compared with men. Finally, the prevalence of vitamin D deficiency significantly increased with abdominal obesity, generalised obesity, the MetS and IR. Further prospective studies are needed to confirm the association between serum $25(\mathrm{OH}) \mathrm{D}$ levels and severity of glucose tolerance. 


\section{Acknowledgements}

The authors thank the participants for their cooperation.

The authors also acknowledge the Research Society for the Study of Diabetes in India (RSSDI) for the financial support for the study through their research grant (project no. RSSDI/ HQ/Grants/2014/250). This is the 156th publication from the CURES.

R. P., R. J. and V. M. conceived the study; R. J. was involved in laboratory analysis; R. P. and R. J. were involved in interpretation of the data and wrote the first and subsequent drafts of the manuscript. U. V. performed the statistical analyses; V. M., R. M. A., M. D. and C. S. S. designed the CURES and critically reviewed the manuscript. All authors contributed to the revision of the manuscript and approved the final submitted version.

The authors declare that there are no conflicts of interest.

\section{References}

1. Holick MF (2011) Vitamin D: a d-lightful solution for health. J Investig Med 59, 872-880.

2. Vimaleswaran KS, Cavadino A, Berry DJ, et al. (2014) Association of vitamin D status with arterial blood pressure and hypertension risk: a mendelianrandomisation study. Lancet Diabetes Endocrinol 2, 719-729.

3. Scragg R, Sowers MF \& Bell C (2004) Serum 25-hydroxyvitamin $\mathrm{D}$, diabetes, and ethnicity in the third National Health and Nutrition Examination Survey. Diabetes Care 27, 2813-2818.

4. Pludowski P, Holick MF, Pilz S, et al. (2013) Vitamin D effects on musculoskeletal health, immunity, autoimmunity, cardiovascular disease, cancer, fertility, pregnancy, dementia and mortality - a review of recent evidence. Autoimmun Rev 12, 976-989.

5. Dhas Y, Mishra N \& Banerjee, J (2017) Vitamin D deficiency and oxidative stress in type 2 diabetic population of India. Cardiovasc Hematol Agents Med Chem 14, 82-89.

6. Scragg R, Holdaway I, Singh V, et al. (1995) Serum 25-hydroxyvitamin $\mathrm{D}_{3}$ levels decreased in impaired glucose tolerance and diabetes mellitus. Diabetes Res ClinPract 27, 181-188.

7. Hutchinson MS, Figenschau Y, Almås B, et al. (2011) Serum 25-hydroxyvitamin D levels in subjects with reduced glucose tolerance and type 2 diabetes - the Tromsø OGTT-study. Int $J$ Vitam Nutr Res. 81, 317-327.

8. Pittas AG, Lau J, Hu FB, et al. (2007). The role of vitamin D and calcium in type 2 diabetes. A systematic review and metaanalysis. J Clin Endocrinol Metab 92, 2017-2029.

9. Wahl, DA, Cooper, C, Ebeling, PR, et al. (2012) A global representation of vitamin D status in healthy populations. Arch Osteoporos 7, 155-172.

10. Dutta, D, Maisnam, I, Shrivastava, A, et al. (2013) Serum vitamin-D predicts insulin resistance in individuals with prediabetes. Indian J Med Res 138, 853-860.

11. Modi, KD, Ahmed, MI, Chandwani, R, et al. (2015) Prevalence of vitamin D deficiency across the spectrum of glucose intolerance. J Diabetes Metab Disord 14, 54.

12. Guan, C, Zhen, D, Tang, X, et al. (2014) The status of 25hydroxyvitamin D across the spectrum of glucose tolerance among middle-aged and elderly Chinese individuals. Clin Endocrinol (Oxf). 81, 834-840.

13. Pittas AG, Dawson-Hughes B, Li T, et al. (2006) Vitamin D and calcium intake in relation to type 2 diabetes in women. Diabetes Care 29, 650-656.
14. Anjana RM, Shanthi Rani CS, Deepa M, et al. (2015) Incidence of diabetes and prediabetes and predictors of progression among Asian Indians: 10-year follow-up of the Chennai Urban Rural Epidemiology Study (CURES) Diabetes Care 38, 1441-1448.

15. Deepa M, Pradeepa R, Rema M, et al. (2003) The Chennai Urban Rural Epidemiology Study (CURES) - study design and methodology (urban component). J Assoc Physicians India 51, 863-870.

16. Jayashri R, Venkatesan U, Rohan M, et al. (2018) Prevalence of vitamin $\mathrm{B}_{12}$ deficiency in South Indians with different grades of glucose tolerance. Acta Diabetol 55, 1283-1293.

17. Harrison GG, Buskirk ER, Lindsay Carter ER, et al. (1988) Skinfold thickness and measurement technique. In Anthropometric Standardization Reference Manual, pp. 5570 [TG Lohman, AF Roche and $\mathrm{R}$ Martorell, editors]. Champaign, IL: Human Kinetics Books.

18. Alberti KG \& Zimmet PZ (1998) Definition diagnosis and classification of diabetes mellitus and its complications. Part 1: diagnosis and classification of diabetes mellitus, provisional report of a WHO consultation. Diabet Med 15, 539.

19. Holick MF, Binkley NC, Bischoff-Ferrari HA, et al.; Endocrine Society (2011) Evaluation, treatment, and prevention of vitamin D deficiency: an Endocrine Society clinical practice guideline. J Clin Endocrinol Metab 96, 1911-1930.

20. World Health Organization (2000) The Asia Pacific perspective. Redefining obesity and its treatment. World Health Organization. International Association for the study of Obesity and International Obesity Task Force. Melbourne: International Diabetes Institute.

21. Chobanian AV, Bakris GL, Black HR, et al. (2003) National Heart, Lung, and Blood Institute Joint National Committee on Prevention, Detection, Evaluation, and Treatment of High Blood Pressure; National High Blood Pressure Education Program Coordinating Committee. The seventh report of the Joint National Committee on Prevention, Detection, Evaluation and Treatment of High Blood Pressure (JNC-7). JAMA 289, 2560-2572.

22. Matthews DR, Hosker JP, Rudenski AS, et al. (1985). Homeostasis model assessment: insulin resistance and beta-cell function from fasting plasma glucose and insulin concentrations in man. Diabetologia 28, 412-429.

23. Alberti KG, Zimmet P \& Shaw J; IDF Epidemiology Task Force Consensus Group (2005) The metabolic syndrome - a new worldwide definition. Lancet 366, 1059-1062.

24. Deepa M, Farooq S, Datta M, et al. (2007) Prevalence of metabolic syndrome using WHO, ATPIII and IDF definitions in Asian Indians: the Chennai Urban Rural Epidemiology Study (CURES-34). Diabetes Metab Res Rev 23, 127-134.

25. Harinarayan CV, Ramalakshmi T \& Venkataprasad U (2004) High prevalence of low dietary calcium and low vitamin D status in healthy south Indians. Asia Pac J Clin Nutr 13, 359-364.

26. Daly RM, Gagnon C, Lu ZX, et al. (2012) Prevalence of vitamin D deficiency and its determinants in Australian adults aged 25 years and older: a national, population-based study. Clin Endocrinol (Oxf) 77, 26-35.

27. Mitchell DM, Henao MP, Finkelstein JS, et al. (2012) Prevalence and predictors of vitamin D deficiency in healthy adults. Endocr Pract 18, 914-923.

28. Looker AC, Johnson CL, Lacher DA, et al. (2011) Vitamin D status: United States, 2001-2006. NCHS Data Brief 59, 1-8.

29. Alkerwi A, Sauvageot N, Gilson G, et al. (2015) Prevalence and correlates of vitamin D deficiency and insufficiency in Luxembourg adults: evidence from the observation of cardiovascular risk factors (ORISCAV-LUX) study. Nutrients 7, 6780-6796. 
30. Hovsepian S, Amini M, Aminorroaya, A, et al. (2018) Prevalence of vitamin D deficiency among adult population of Isfahan City, Iran. J Health Popul Nutr 29, 149-155.

31. Zargar AH, Ahmad S, Masoodi SR, et al. (2007) Vitamin D status in apparently healthy adults in Kashmir Valley of Indian subcontinent. Postgrad Med J 83, 713-716.

32. Marwaha RK, Tandon N, Garg MK, et al. (2011) Vitamin D status in healthy Indians aged 50 years and above.J Assoc Physicians India 59, 706-709.

33. Garg R, Agarwal V, Agarwal P, et al. (2018) Prevalence of vitamin $\mathrm{D}$ deficiency in Indian women. Int $J$ Reprod Contracept Obstet Gynecol 7, 2222-2225.

34. Chowdary R, Nellutla R \& Prasad Reddy K (2014) Vitamin D status in a random population: a comparative study between males and females. Int J Sci Res 3, 19-21.

35. Harinarayan CV, Ramalakshmi T, Prasad UV, et al. (2008) Vitamin D status in Andhra Pradesh: a population based study. Indian J Med Res 127, 211-218.

36. Palomer X, González-Clemente JM, Blanco-Vaca F, et al. (2008) Role of vitamin D in the pathogenesis of type 2 diabetes mellitus. Diabetes Obes Metab 10, 185-197.

37. Danescu LG, Levy S \& Levy J (2009) Vitamin D and diabetes mellitus. Endocrine 35, 11-17.

38. Parekh D, Sarathi V, Shivane VK, et al. (2010) Pilot study to evaluate the effect of short-term improvement in vitamin $D$ status on glucose tolerance in patients with type 2 diabetes. Endocr Pract 16, 600-608.

39. Von Hurst PR, Sonehouse W \& Coad J (2010) Vitamin D supplementation reduces insulin resistance in South Asian women living in New Zealand who are insulin resistant and vitamin D deficient: a randomized, placebo-controlled trial. Br J Nutr 103, 549-555.

40. Scragg R, Sowers MF \& Bell C (2004) Serum 25-hydroxyvitamin $\mathrm{D}$, diabetes, and ethnicity in the third National Health and Nutrition Examination Survey. Diabetes Care 27, 2813-2818.

41. Akter S, Kuwahara K, Matsushita Y, et al. (2020) Serum 25-hydroxyvitamin $\mathrm{D}(3)$ and risk of type 2 diabetes among Japanese adults: the Hitachi Health Study. Clin Nutr 39, 1218-1224.

42. Reddy GB, Sivaprasad M, Shalini T, et al. (2015) Plasma vitamin $\mathrm{D}$ status in patients with type 2 diabetes with and without retinopathy. Nutrition 31, 959-963.

43. Braun TR, Been LF, Blackett PR, et al. (2012) Vitamin D deficiency and cardio-metabolic risk in a north Indian community with highly prevalent type 2 diabetes. J Diabetes Metab 3 1000213.

44. Nur-Eke R, Özen M, Cekin AH, et al. (2019) Pre-diabetics with hypovitaminosis D. Have higher risk for insulin resistance. Clin Lab 65

45. Pinelli NR, Jaber LA, Brown MB, et al. (2010) Serum 25-hydroxy vitamin $\mathrm{D}$ and insulin resistance, metabolic syndrome, and glucose intolerance among Arab Americans. Diabetes Care 33, 1373-1375.

46. Shankar A, Sabanayagam C, Kalidindi S, et al. (2011) Serum 25-hydroxyl vitamin D levels and prediabetes among subjects free of diabetes. Diabetes Care 34, 1114-1119.

47. Srinath KM, Shashidhara KC, Rajeev Reddy G, et al (2016) Pattern of vitamin D status in prediabetic individuals: a case-control study at tertiary hospital in South India. Int J Res Med Sci 4, 1010-1015.
48. Bhatt SP, Misra A, Gulati S, Singh N, et al. (2018) Lower vitamin D levels are associated with higher blood glucose levels in Asian Indian women with pre-diabetes: a population-based cross-sectional study in North India. BMJ Open Diabetes Res Care 6, e000501.

49. Palazhy S, Viswanathan V, Muruganathan A, et al. (2017) Prevalence of 25-hydroxy vitamin D deficiency among type 2 diabetic subjects of South India. Int J Diabetes Dev Ctries 37, 69-73.

50. Kostoglou-Athanassiou I, Athanassiou P, Gkountouvas A, et al. (2013) Vitamin D and glycemic control in diabetes mellitus type 2. Ther Adv Endocrinol Metab 4, 122-128.

51. Darraj H, Badedi M, Poore KR, et al. (2019) Vitamin D deficiency and glycemic control among patients with type 2 diabetes mellitus in Jazan City, Saudi Arabia. Diabetes Metab Syndr Obes 12, 853-862.

52. Sahasrabuddhe AV, Pitale SU, Gupta M, et al. (2017) Study of vitamin $D$ levels and its correlation with insulin resistance. Natl J Physiol Pharm Pharmacol 7, 963-967.

53. Ford ES, Ajani UA, McGuire LC, et al. (2005). Concentrations of serum vitamin $\mathrm{D}$ and the metabolic syndrome among U.S. adults. Diabetes Care 28, 1228-1230.

54. Gulseth HL, Gjelstad IM, Tierney AC, et al. (2010) Serum vitamin $\mathrm{D}$ concentration does not predict insulin action or secretion in European subjects with the metabolic syndrome. Diabetes Care 33, 923-925.

55. Chiu KC, Chu A, Go VL, et al. (2004) Hypovitaminosis D is associated with insulin resistance and beta cell dysfunction. Am J Clin Nutr 79, 820-825.

56. Kayaniyil S, Vieth R, Retnakaran R, et al. (2010) Association of vitamin $\mathrm{D}$ with insulin resistance and $\beta$-cell dysfunction in subjects at risk for type 2 diabetes. Diabetes Care $\mathbf{3 3}$, 1379-1381.

57. Lu L, Yu Z, Pan A, et al. (2009) Plasma 25-hydroxyvitamin D concentration and metabolic syndrome among middleaged and elderly Chinese individuals. Diabetes Care 32, 1278-1283.

58. Pereira-Santos M, Costa PR, Assis AM, et al. (2015) Obesity and vitamin D deficiency: a systematic review and meta-analysis. Obes Rev 16, 341-349.

59. Cheng S, Massaro JM, Fox CS, et al. (2010) Adiposity, cardiometabolic risk, and vitamin D status: the Framingham Heart Study. Diabetes 59, 242-248.

60. Durmaz ZH, Demir AD, Ozkan T, et al. (2017) Does vitamin D deficiency lead to insulin resistance in obese individuals? Biomed Res (India) 28, 7491-7497.

61. Harinarayan CV \& Joshi SR (2009) Vitamin D status in India - its implications and remedial measures. J Assoc Physicians India 57, 40-48.

62. Babu US \& Calvo MS (2010) Modern India and the vitamin D dilemma: evidence for the need of a national food fortification program. Mol Nutr Food Res. 54, 1134-1147.

63. Agarwal KS, Mughal MZ, Upadhyay P, et al. (2002) The impact of atmospheric pollution on vitamin D status of infants and toddlers in Delhi, India. Arch Dis Child 87, 111-113.

64. Marwaha RK \& Dabas A (2019) Interventions for prevention and control of epidemic of vitamin $\mathrm{D}$ deficiency. Indian J Pediatr 86, 532-537.

65. Tiwari L \& Puliyel JM (2004) Vitamin D level in slum children of Delhi. Indian Pediatr 41, 1076-1077. 